\title{
ASSESSMENT OF SEVERITY OF ULCERATIVE COLITIS ON FIRST COLONOSCOPIC EXAMINATION
}

\author{
Rabia Tariq, Anum Abbas, Ehtesham Haider, Usama Bin Zubair*, Farrukh Saeed, Zafar Ali Qureshi \\ Pak Emirates Military Hospital/National University of Medical Sciences (NUMS) Rawalpindi Pakistan, *Pakistan Institute of Medical \\ Sciences, Islamabad Pakistan
}

\begin{abstract}
Objective: To assess the severity of ulcerative colitis on first colonoscopic examination.

Study Design: Prospective cross-sectional (correlational) study design.

Place and Duration of Study: Study was conducted in Gastroenterology Outpatient Department of Pak Emirates Military Hospital, Rawalpindi, from Nov 2017 to Oct 2018.

Methodology: An aggregate of 200 patients within the age range of 12-70 years, were included in the study through non-probability consecutive sampling. The data was collected by the self-administered questionnaire including age, gender, stool frequency, P/R bleed, systemic features of ulcerative colitis \& colonoscopic findings. Effectiveness of the procedures was noted on a pre-designed performa and the endoscopic assessment was based upon mayo score severity of colitis graded from Normal (0) to Severe (3). Data was analyzed by using SPSS-19.

Results: The mean age of the participants was reported $38 \pm 2.1$ years. Out of 200 participants $104(52 \%)$ were male, diarrhea with PR bleed was positive in 180 (90\%) \& anemia in 154 (77\%). Colonoscopic findings showed that $72(36 \%)$ were with Left sided colitis (Montreal Class E2) \& 82 (41\%) with proctitis (Montreal class E1). Severe disease (Mayo endoscopic Score 3) was positive in 118 (59\%) patients.

Conclusion: Assessment of severity of UC is important as it determines the long term management \& also valuable for risk stratification to predict the prognosis. Our findings feature the requirement for system level enhancements to encourage the proper delivery of colonoscopy services dependent on individual risk.
\end{abstract}

Keywords: Activity index, Colonoscopy, Disease severity, Inflammatory bowel disease, Ulcerative colitis.

This is an Open Access article distributed under the terms of the Creative Commons Attribution License (http://creativecommons.org/licenses/by/4.0), which
permits unrestricted use, distribution, and reproduction in any medium, provided the original work is properly cited.

\section{INTRODUCTION}

Ulcerative colitis is an idiopathic, chronic inflammatory disorder of the colonic mucosa, which usually involves the rectum and extends proximally in a consistent way through piece of, or whole colon; however few patients with proctitis or left-sided colitis may have a ceacal involvement. Rectal bleed along with increased stool frequency are common symptom of the disease. The clinical course is erratic, set apart by exchanging times of intensification and remission. Ulcerative colitis and Crohn's infection are the two principle types of inflammatory bowel disease. Despite some mutual attributes, these structures can be recognized by contrasts in hereditary inclination, risk factors, clinical, endoscopic, and histological highlights. The etiology of ulcerative

Correspondence: Dr Rabia Tariq, Resident Gastroenterology, Pak Emirates Military Hospital, Rawalpindi Pakistan

Received: 16 Apr 2019; revised received: 01 Jun 2019; accepted: 25 Jun 2019 colitis is still unknown although hereditary lineage, immune phenomenon are possible hypothesis.

Inflammation in ulcerative colitis is naturally confined to the mucosal surface. Disease conveyance is stratified by the degree of colonic association, from proctitis to left-sided colitis or pancolitis $^{2}$. For assessment of disease activity factors that need to be considered are clinical symptoms, quality of life, endoscopic findings \& histology. Endoscopy is important for establishing the diagnosis of UC \& differentiating it from Crohn's \& other forms of colitis. Endoscopic assessment of mucosal details is the main parameter used by clinicians to assess the extent \& severity of disease. Disease extent \& severity determines the treatment \& prognosis.

Atleast ten scoring systems have been devised for assessment of disease activity in UC since the development of first such score by 
Baron et $\mathrm{al}^{3}$. Baron \& Mayo score are most widely used in clinical trials. The mayo score ranges from 0-12 with higher score corresponding with more severe disease. The endoscopic sub-score ranges from 0-3 (0-normal, 1-mlid, 2-moderate, 3severe). Patients with long-standing UC confront an expanded risk for colitis-related stricture, dysplasia and colorectal cancer. Factors related with expanded hazard for malignancy incorporate family history of sporadic colorectal cancer (two fold increased risk), broad colonic contribution (pancolitis), primary sclerosing cholangitis (four-fold increased risk), backwash ileitis ${ }^{4,6}$. Based on these perceptions, colonoscopic reconnaissance in patients with long-standing UC is exceptionally suggested.

For assessment of disease activity clinicians can use separate scoring systems for clinical symptoms, endoscopy, and histology or can use a composite score like Mayo clinical Index that combines endoscopic findings with symptoms. Though composite score is simple to use but its drawback is failure to validate individual factor. Endoscopic findings are most often assessed on fixed point scales, or essentially depicted by dichotomous factors (present/absent) ${ }^{11}$. However, endoscopic highlights of mucosal inflammation are ceaseless factors presenting potential drawbacks with discrete scales for scoring \& is operator dependent.

The point of this study was to assess endoscopic severity \& disease activity of UC on first presentation. Also to evaluate indicators of mucosal inflammation in UC, the between spectator understanding, the difference of the mean score, and the impact of the observer's involvement.

\section{METHODOLOGY}

A total of 200 patients who reported to Gastroenterology Outpatient Department of Pak Emirates Military Hospital Rawalpindi, from Nov 2017 to Oct 2018 participated in this crosssectional study. Sample size of the study was calculated through WHO sample size calculator at $95 \%$ confidence interval, $5 \%$ a and power of study was taken as $80 \%$. The individuals were selected on the basis that they were in the age range of 12 to 70 years had large bowel diarrhea for $>6$ weeks, Bleeding $P / R$, Systemic features of UC and Mayo score assessment (table-I) $(0,1,2$, 3 point) on colonoscopy and excluded the cases that were already diagnosed of ulcerative colitis, colonic Malignancy, prior history of abdominal surgery, palpable abdominal mass and prior history of colonic radiotherapy. The data was collected by the interview based questionnaire.

The study was approved by the ethical review board of hospital and research department of CPSP. Participants were given full liberty of participating voluntarily and those who choose to be a part of the study signed a written consent form before the study was initiated.

Data was analyzed by using SPSS version 19.0. Mean \pm SD were presented for quantitative variables like age, frequency of Bowel habits. Frequency and percentage were computed for qualitative variables like gender, disease extent \& severity. Binary logistic regression analysis was done to evaluate the significance of relationship of various factors with the presence of severity of illness.

\section{RESULTS}

A total of 200 patients were taken in the study. Out of those 200 individuals 104 (52\%) were male while 96 (48\%) were females. The mean age of the study participants was $38 \pm 2.1$ years. Diarrhea with PR Bleed was reported positive in $180(90 \%)$ of patients while only 20 $(10 \%)$ had negative report for this.

One hundred thiry five $(67.5 \%)$ participants had Colicky abdominal pain while 65 (32.5\%) had negative report. For anemia 154 (77\%) of participants report positive and negative in 46 (23\%). According to severe disease i-e with endoscopic Mayo Score 3, 61 were males \& 57 were females.

On $\mathrm{H} / \mathrm{P}$, UC was reported in $78(39 \%)$ of cases with severe UC in $54(27 \%)$, followed by chronic active UC in $18(9 \%)$, then Moderate active colitis in $28(14 \%)$ while Mild disease in 22 
$(11 \%)$ of participants. Female gender was associated with presence of severe illness (table-I).

Table-I: Endoscopic index of severity.

\begin{tabular}{c|l}
\hline Mayo Score & Endoscopic Assesment \\
\hline 0 & Normal / Inactive Colitis \\
\hline 1 & $\begin{array}{l}\text { Mild Colitis: Mild friability, erythema, } \\
\text { decrease in vascularity }\end{array}$ \\
\hline 2 & $\begin{array}{l}\text { Moderate Colitis: Friability, marked } \\
\text { erythema, absent vascular pattern, } \\
\text { erosions seen }\end{array}$ \\
\hline 3 & $\begin{array}{l}\text { Severe Colitis: Ulcerations and spont- } \\
\text { aneous bleeding }\end{array}$ \\
\hline
\end{tabular}

Table-II: The correlated factors relating to the presence of severe illness the target population: the binary logistic regression

\begin{tabular}{l|c|c}
\hline & $\boldsymbol{p}$-value & OR (95\% CI) \\
\hline Age (ref. is <30 years) & 0.718 & $1.134(0.574-2.241)$ \\
\hline Gender (ref. is male) & 0.000 & $0.315(0.175-0.568)$ \\
\hline $\begin{array}{l}\text { Duration of illness } \\
\text { (ref. is <2 years) }\end{array}$ & 0.633 & $0.864(0.473-1.578)$ \\
\hline
\end{tabular}

\section{DISCUSSION}

Ulcerative colitis (UC) was described as a disease entity in the nineteenth century, however it took until the point when the Second World War for the main clinical investigations to be led.

Although different types of non-infectious chronic diarrhea were described in old occasions, the term 'ulcerative colitis' was first used in a paper by Sir Samuel Wilks in 185914,15. He depicted a dissection on a 42-year-elderly person who died following a while of diarrhoea ${ }^{15}$. This lady had, undoubtedly, transmural inflammation of the terminal ileum and the colon and consequently she had capitulated to Crohn's ailment (CD), which was just perceived as a different element around 70 years after the fact ${ }^{16}$.

Ulcerative Colitis clinical course comprises the period of remission \& relapse. At the time of being diagnosed most patients have mildmoderate disease whereas less than $10 \%$ have severe symptoms ${ }^{4}$. In contrast to CD, UC has for quite a while been viewed as a fairly amiable illness, but with an expanded risk of colorectal cancer and some basic damage ${ }^{17}$.

Similar to the case for $C D$, most restorative methodologies depended on manifestation con- trol until the 2000s. It has now turned out to be evident that stringent disease control, including mucosal mending, is the best consideration for the patient, giving a decreased danger of ailment backslide, hospitalization, surgery and cancer ${ }^{18,19}$.

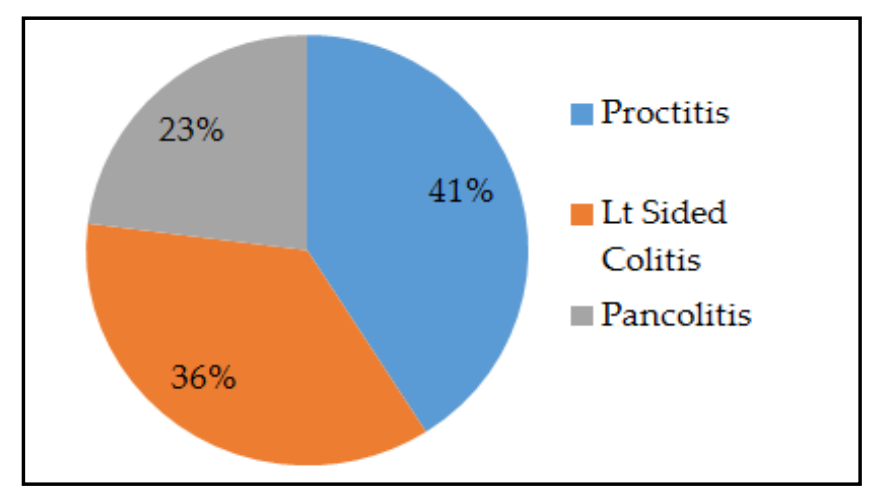

Figure-1: Extent of the disease depending upon the colonic involvement.

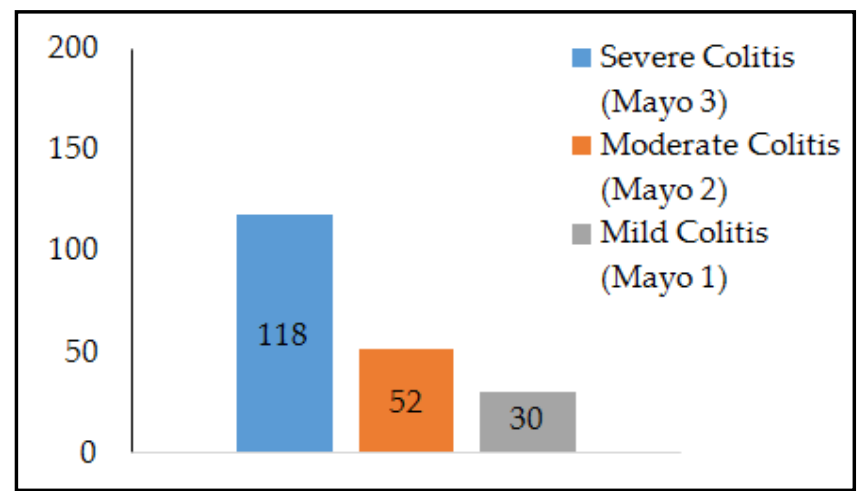

Figure-2: Severity of colitis (mayo endoscopic score).

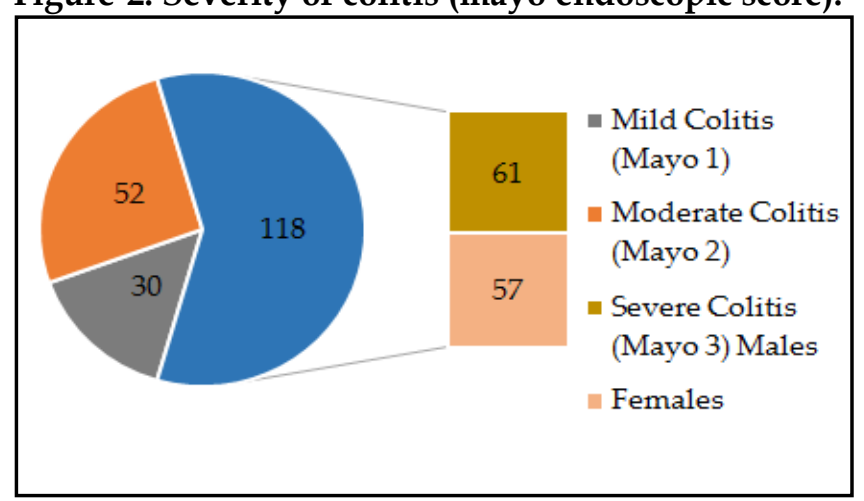

Figure-3: Frequency of severity of colitis.

Therefore, treatment objectives have moved after some time from clinical response to mucosal healing. In this unique circumstance, endoscopic scores are progressively utilized in both clinical practice and clinical preliminaries in UC patients. Manuel et al stated that there is increased risk of 
relapse in patients with endoscopic Mayo score of 1 as compared with a score of 020 . Advancement in imaging techniques like advent of chromeendoscopy, magnification endoscopy has led to detailed direct visualization of mucosal details \& vasculature. But still the assessment is operator dependent, and description of endoscopic findings like friability, erosions \& submucosal vascular pattern need a lot of training. Clinical trials show good inter-observer agreement among the experienced endoscopists in UC related endoscopic features.

Analysis of ulcerative colitis depends on clinical indications affirmed by target findings from endoscopic and histological examinations ${ }^{23}$. Inflammation for the most part begins in the rectum and expands proximally. Reliant on the colonic sections included, malady degree can be named proctitis, left-sided colitis, or pancolitis. Proctitis is inflammation extending upto $15 \mathrm{~cm}$ from anal verge, this disease extent according to Montreal classification is E1, left sided colitis upto splenic flexure known as E2 according to Montreal classification \& pancolitis is extension beyond that, E3 according to Montreal. Degree ought to be surveyed at conclusion, as it is fundamental for determination of treatment strategy, and has prognostic value for median to long term survival. Chances of progression to pancolitis is $25-50 \%$ in patients with proctitis whereas $21 \%$ in those with disease proximal to sigmoid colon ${ }^{10}$. Endoscopic assessment is operator dependent, despite different scoring systems much more data is needed to validate a simplified score with international agreement to decide whether a single index or combination of indices should be used to assess disease activity.

In this investigation findings showed that the pancolitis was found in $46(23 \%)$ (fig- 1$)$. The study of Sahami et al, stated $34 \%$ of patients have infection restricted to the rectum or the sigmoid colon (distal colitis), 37.3\% have left-sided colitis, and around $28.6 \%$ have pancolitis ${ }^{24}$. Patients with primary sclerosing cholangitis, will probably have broad malady at presentation than others. Illness flares related with movement of anatomic degree (eg, from proctitis to left-sided colitis or pancolitis) normally pursue an extreme course and require more escalated restorative treatment than do non-dynamic flares ${ }^{25}$. The anatomical degree of mucosal inflammation is unmistakably a standout amongst the most critical elements deciding disease course; patients with more serious infection have a tendency to extensive colitis than those with less extreme sickness. Moreover, extent of involvement is an imperative indicator of colectomy and colorectal cancer. Colectomy rates at 10 years are $5 \%$ in patients with proctitis, expanding to $19 \%$ in those with pancolitis ${ }^{22}$.

Limitations of our study are, first it's a single center study as it has not been evaluated by physicians with varying experience among different centers. Secondly it comprises of limited data, much larger number of patients required to validate the implementation of this in further research trials \& clinical practice.

\section{CONCLUSION}

Assessment of severity of UC is important as it determines the long term management \& also valuable for risk stratification to predict the prognosis. Our findings feature the requirement for system level enhancements to encourage the proper delivery of colonoscopy dependent on individual risk.

\section{ACKNOWLEDGEMENT}

We are grateful for the support of all the doctors included in the study.

\section{CONFLICT OF INTEREST}

There is no conflict of interest to be declared by any author.

\section{REFERENCES}

1. Ananthakrishnan A. Environmental risk factors for inflammatory bowel diseases: a review. Digest Dis Sci 2015; 60(2): 290-98.

2. Shergill A, Lightdale J, Bruining D, Acosta R, Chandrasekhara V, Chathadi $\mathrm{K}$, et al. The role of endoscopy in inflammatory bowel disease. Gastroint Endosc 2015; 81(5): 1101-21.

3. Vuitton L, Peyrin-Biroulet L, Colombel J, Pariente B, Pineton de Chambrun G, Walsh A, et al. Defining endoscopic response and remission in ulcerative colitis clinical trials: an international consensus. Aliment Pharmacol Ther 2017; 45(6): 801-13.

4. UpToDate [Internet]. Uptodate.com. 2015 [cited 16 November 2018]. Available from: https://www.uptodate.com/contents/ 
definition-epidemiology-and-risk-factors-in-inflammatorybowel-disease

5. Kalkan I, Dagli U, Kekilli M, Oztas E, Tunc B, Ulker A. Clinical course and predictors of total colectomy in ulcerative colitis; a referral center experience from Turkey. Turk J Gastroenterol 2015; 26(1): 25-30.

6. Iannone A, Ruospo M, Wong G, Principi M, Barone M, Strippoli $\mathrm{G}$, et al. Chromoendoscopy for surveillance in ulcerative colitis and crohn's disease: A systematic review of randomized trials. Clin Gastroenterol Hepatol 2017; 15(11): 1684-97.

7. Dulai P, Sandborn W, Gupta S. Colorectal cancer and dysplasia in inflammatory bowel disease: a review of disease epidemiology, pathophysiology, and management. Cancer Prev Res 2016; 9(12): 887-94.

8. Marion J, Sands B. The SCENIC consensus statement on surveillance and management of dysplasia in inflammatory bowel disease: praise and words of caution. Gastroenterol 2015; 148(3): $462-67$.

9. Carballal S, Maisterra S, López-Serrano A, Gimeno-García A, Vera M, Marín-Garbriel J, et al. Real-life chromoendoscopy for neoplasia detection and characterisation in long-standing IBD. Gut 2016; 67(1): 70-78.

10. Wanderas M, Moum B, Hoivik M, Hovde O. Predictive factors for a severe clinical course in ulcerative colitis: Results from population-based studies. World J Gastrointest Pharmacol Ther 2016; 7(2): 235-40.

11. Mohammed N, Subramanian V. Clinical relevance of endoscopic assessment of inflammation in ulcerative colitis: Can endoscopic evaluation predict outcomes?. World J Gastroenterol 2016; 22(42): 9324.

12. Arai M, Naganuma M, Sugimoto S, Kiyohara H, Ono K, Mori K, et al. The ulcerative colitis endoscopic index of severity is useful to predict medium- to long-term prognosis in ulcerative colitis patients with clinical remission. J Crohn's Colitis 2016; 10(11): 1303-09.

13. Levesque B, Sandborn W, Ruel J, Feagan B, Sands B, Colombel J. Converging goals of treatment of inflammatory bowel disease from clinical trials and practice. J Gastroenterol 2015; 148(1): 3751.

14. Hindryckx P, Baert F, Hart A, Magro F, Armuzzi A, PeyrinBiroulet L. Clinical trials in ulcerative colitis: a historical pers- pective. J Crohn's Colitis 2015; 9(7): 580-88.

15. Lin C, Wei S, Lin B, Tsai W, Chen J, Hsu T, et al. A retrospective analysis of 20-year data of the surgical management of ulcerative colitis patients in Taiwan: a study of Taiwan Society of Inflammatory Bowel Disease. Intest Res 2016; 14(3): 248-52.

16. Connelly T, Malik Z, Sehgal R, Coffey J, Peirce C. Should surgical intervention become a primary treatment modality in Crohn's disease? A review of the role of surgery and emerging surgical techniques. Mesent Periton 2018; 2(1): 2-2.

17. Burisch J, Munkholm P. The epidemiology of inflammatory bowel disease. Scand J Gastroenterol 2015; 50(8): 942-51.

18. Tursi A, Elisei W, Picchio M, Forti G, Penna A, Inchingolo C, et al. Histological inflammation in ulcerative colitis in deep remission under treatment with infliximab. Clini Res Hepatol Gastroenterol 2015; 39(1): 107-13.

19. Shah S, Colombel J, Sands B, Narula N. Mucosal healing is associated with improved long-term outcomes of patients with ulcerative colitis: a systematic review and meta-analysis. Clini Gastroenterol Hepatol 2016; 14(9): 1245-55.e8.

20. Barreiro-de Acosta M, Vallejo N, de la Iglesia D, Uribarri L, Bastón I, Ferreiro-Iglesias R, et al. Evaluation of the risk of relapse in ulcerative colitis according to the degree of mucosal healing (Mayo 0 vs 1): A longitudinal cohort study. J Crohn's Colitis 2015; 10(1): 13-19.

21. Christensen B, Rubin D. Understanding endoscopic disease activity in IBD: How to incorporate it into practice. Curr Gastroenterol Rep 2016; 18(1): 11-19.

22. Reinisch W, Reinink A, Higgins P. Factors associated with poor outcomes in adults with newly diagnosed ulcerative colitis. Clini Gastroenterol Hepatol 2015; 13(4): 635-42.

23. Peyrin-Biroulet L, Panés J, Sandborn W, Vermeire S, Danese S, Feagan B, et al. Defining disease severity in inflammatory bowel diseases: Current and future directions. Clini Gastroenterol Hepatol 2016; 14(3): 348-54.e17.

24. Sahami S, Konté K, Buskens C, Tanis P, Löwenberg M, Ponsioen C, et al. Risk factors for proximal disease extension and colectomy in left-sided ulcerative colitis. United Eur Gastroenterol J 2016; 5(4): 554-62.

25. Walsh A, Bryant R, Travis S. Current best practice for disease activity assessment in IBD. Nat Rev Gastroent Hepatol 2016; 13(10): 567-79. 